\section{LA DOMESTICACIÓN DEL PAISAJE DURANTE LA EDAD DEL BRONCE GALLEGO}

\section{THE DOMESTICATION OF LANDSCAPE IN THE GALICIAN BRONZE AGE}

\section{FIDEL MÉNDEZ FERNÁNDEZ (*)}

La noche donde tanteamos es demasiado oscura como para que nos asentemos a afirmar nada sobre ella: ni siquiera que está destinada a durar.

(Lévi-Strauss, 1992: 282)

\section{RESUMEN}

Partiendo del estudio de un conjunto de hábitats de una zona de Galicia se define un nuevo tipo de yacimiento habitacional. Esta definición sirve de base para una revisión del paisaje social de la Edad del Bronce en el Noroeste, en la cual se realizan algunas consideraciones sobre fenómenos que no se incluyen en el mundo de los hábitats (enterramientos y grabados rupestres), pero que, evidentemente, contribuyen a formar el conjunto del paisaje social.

\section{ABSTRACT}

This paper deals with a set of Bronze Age domestic sites from the inner part of Galicia. Through them a specific model of settlement and site formation is proposed which is very helpful in the study of the social landscape of this period in the prehistory of Nort-west Iberia. Evidence of other phenomena, which includes barrows and funerary sites and rock art, is also considered, and contributes to the formation of the social landscape.

* Grupo de Trabajo en Arqueología del Paisaje/ Impacto Arqueológico en Obras Públicas. Departamento de Historia 1. Facultade de Xeografía e Historia. Universidade de Santiago de Compostela. 15703 Santiago de Compostela.

El artículo fue remitido en su versión final el 7-III-94.
Palabras clave: Arqueología del paisaje. Sociedad. Edad del Bronce. Noroeste. Procesos de formación. Hábitat. Petroglifos. Enterramientos.

Key words: Landscape archaeology. Society. Bronze Age. North-west Spain. Formation processes. Settlement. Rock carvings. Burials.

\section{PLANTEAMIENTOS}

El tema de este trabajo (1) es el paisaje durante la Edad del Bronce en Galicia. Para tratar este asunto pretendemos recorrer un camino

(1) Este trabajo se enmarca dentro de la línea de investigación en Arqueología del Paisaje que se desarrolla en la Universidad de Santiago (Departamento de Historia I) a través del proyecto "A Culturización da Paisaxe Prehistórica", financiado en 1992 y 1993 por la D.X.P.H.D. de la Xunta de Galicia. Quiero agradecer a mis compañeros del Grupo de trabajo en Arqueología del paisaje/Impacto Arqueológico en Obras Públicas las facilidades que me han dado para su realización, concretamente Anxo Rodriguez Paz ha preparado y delineado, con la solvencia que le caracteriza, la totalidad de la parte gráfica. Es evidente que muchas de las ideas vertidas en el texto se benefician de los años de formación, trabajo, conversaciones y discusiones con Felipe Criado y el resto de mis compañeros. También quiero agradecer especialmente a Felipe Criado y a Pilar Prieto que hayan revisado el texto haciéndome notar los muchos errores que en él se introducían. 
de tres niveles distintos y simultáneos para a través de ellos, visitar lugares nuevos y otros ya conocidos. Estos niveles van de lo más concreto a lo general, o si se quiere, de lo más práctico a lo más conceptual. En el primero de ellos, que presenta un carácter geográfico, se partirá de una zona de estudio concreta, la Sierra de O Bocelo y el Valle del río Furelos (Fig. 1), para visitar otras zonas de Galicia y del Norte de Portugal. El segundo de los niveles de nuestro camino nos lleva a recorrer los hábitats de la Edad del Bronce, pero a lo largo de él nos encontraremos con otras manifestaciones de la época que completarán o matizarán la visión obtenida de aquellos. Por último, el tercer nivel nos lleva a partir del paisaje para tratar de avanzar en el conocimiento de la sociedad y la cultura que lo construyó.

Es éste, sin duda, un plan complejo, ambicioso y, a la vez, difuso; pero sinceramente creemos que es la única forma de tratar con realidades, que en definitiva son también complejas,

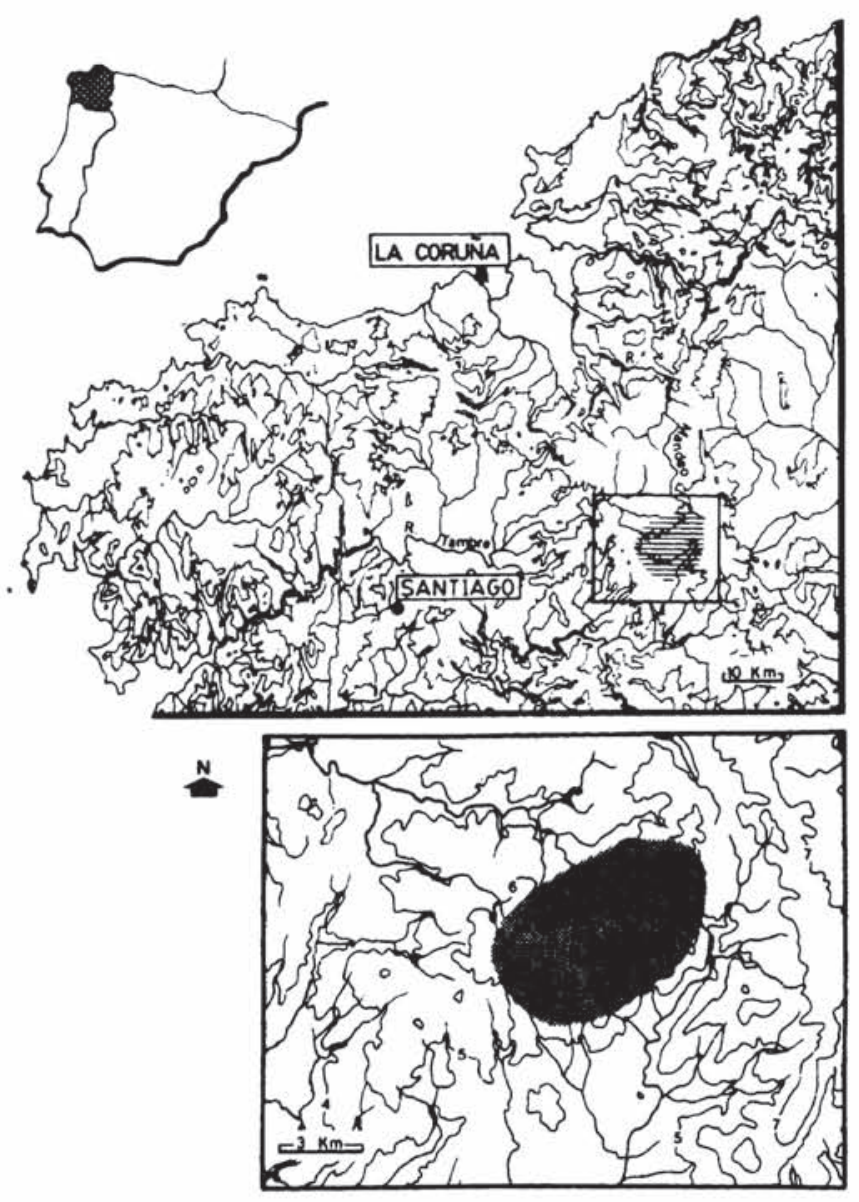

Fig. 1 Situación de la sierra de O Bocelo en el conjunto de Galicia y de la Península. amplias y, a la vez, difusas. Con el conjunto de los tres niveles se pretende extraer una visión general que valore más los aspectos comunes que los diferenciadores, más el conjunto del camino que los hitos señeros. Obviamente, no intentamos, y mucho menos de partida, que estemos tratando con una cuestión uniforme en un espacio determinado a lo largo de un período; es decir, no creemos que el paisaje de la Edad del Bronce en Galicia se constituya en los inicios de esta época con unas características concretas que permanezcan hasta el final de la misma. Los elementos diferenciadores, acotadores y dinámicos existen y tienen una gran importancia, que debe ser valorada en su justa medida. Sin embargo, si logramos encontrar un hilo conductor, será más fácil trabajar con esos aspectos de naturaleza más parcial. El hilo conductor debe buscarse en los aspectos socio-culturales, y a ellos es más fácil llegar por medio del paisaje.

Sin embargo, el trabajo ha de adoptar una forma más concreta y manejable que la que se ha expuesto hasta aquí. Por ello hemos preferido una estructura que permita conjugar los distintos niveles descritos con una exposición más lineal. Como se ha señalado, el tema central de este trabajo es el paisaje de la Edad del Bronce en Galicia. Para profundizar en su conocimiento hemos comenzado analizando un conjunto de yacimientos de la Sierra de O Bocelo y del Valle del Furelos, donde se definirá un nuevo tipo de yacimiento (2). A continuación se realizará un comentario sobre los enterramientos de la Edad del Bronce localizados en esta zona, para así completar la visión del paisaje que nos ofrecen los hábitats. Por último se comparará la realidad observada con ejemplos de otras zonas de Galicia y el Norte de Portugal, en la que se incluye un breve apunte sobre los grabados rupestres, fenómeno de naturaleza eminentemente espacial, que resulta imprescindible tomar en consideración a la hora de aproximarnos al paisaje de la Edad del Bronce en el Noroeste.

Nuestro presupuesto práctico fundamental es aceptar que los datos empíricos no son los que hacen progresar nuestro conocimiento me-

(2) Los trabajos realizados en los yacimientos de la Edad del Bronce se enmarcan en el proyecto general de Arqueología del paisaje en el área Bocelo-Furelos (Criado Boado et alii, 1991). 
diante un mecanismo acumulativo de 'hechos objetivos', únicamente entendible desde un punto de vista positivista, sino el análisis y la reflexión sobre ellos. Por lo tanto creemos imprescindible apuntar, siquiera sea de forma muy somera, la perspectiva adoptada en nuestra investigación y que no es otra que lo que se puede dar en llamar Arqueología del Paisaje. Así pues debemos definir algunos conceptos básicos. La concepción del paisaje que utilizaremos en este trabajo considera a éste como la objetivación de prácticas culturales desarrolladas socialmente (3), tanto de carácter material como imaginario, que se articulan dialécticamente con el medio (Criado Boado, 1993a).

Sin embargo, nuestro objetivo último, utópico deberíamos decir, no se centra exclusivamente en esas prácticas sino en la cultura misma. En este aspecto es útil tener en cuenta la metáfora propuesta por Bourdieu (1991) que hace corresponder la cultura con la lengua y las prácticas, en su caso conducta, con el habla, es decir: las prácticas no constituyen en sí mismas la estructura cultural, sino que conforman una instancia distinta aunque relacionada con ella de una forma similar a como el habla se relaciona con la lengua (Fig. 2). También debemos considerar que nosotros no accedemos directamente a las prácticas sino a un subconjunto de ellas, que se concretan en forma material, y que nos vienen dadas dentro del Registro Arqueológico. Así pues no debemos olvidar que, cuando como arqueólogos iniciamos el trabajo, nos encontramos cuatro peldaños por debajo del punto al cual queremos llegar.

Como ha mostrado F. Criado (1993b), existen algunos posibles mecanismos que nos permiten pasar del nivel inicial al final sin perdidas de información, cuando se tratan directamente aspectos que, como la visibilidad, están determinados por el sistema de Saber-Poder y constituyen rasgos formales directos del fenómeno estudiado.

Sin embargo, en otros aspectos o niveles de significación, la pérdida de información es constante al pasar de un peldaño al siguiente. El Registro Arqueológico no nos permite acceder al

(3) El concepto de objetivación de las prácticas está tomado originalmente del hermoso trabajo de Veyne, 1984: 213 (vease también Bourdieu, 1991, y para la utilización arqueológica de las prácticas sociales Shanks y Tilley, 1992: 122-5 y Barret, 1994: 94-97)

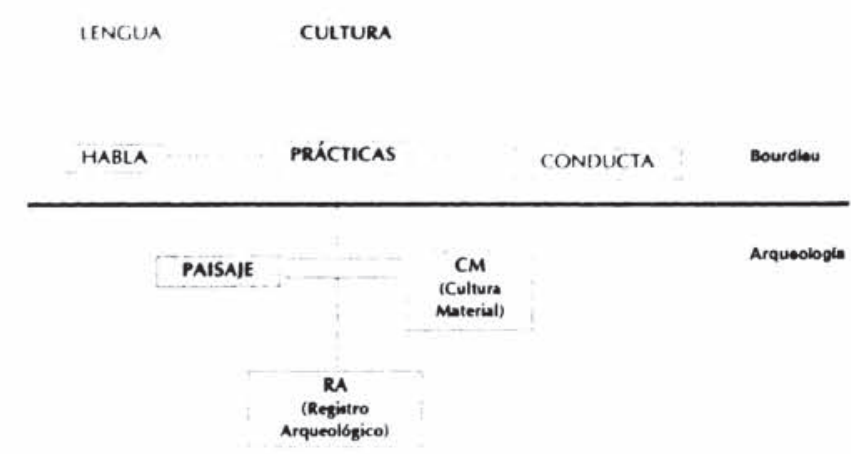

Fig. 2. La analogía de Bourdieu aplicada al caso arqueológico.

conjunto de las prácticas materiales, éstas no representan el conjunto de las prácticas culturales, y éstas últimas no nos ofrecen en sí mismas todas las claves de la estructura o racionalidad cultural. De todas formas como arqueólogos debemos intentar lograr un conocimiento del contexto cultural, para lo cual debemos recorrer el camino, ciertamente complicado, que acabamos de describir y que supone partir de una fracción de la realidad empírica para tratar de llegar a una síntesis significante por medio de la reconstrucción de un aspecto perteneciente al ámbito de la simplicidad conceptual (Lévi-Strauss, 1964). Lo que acabamos de exponer resulta ciertamente difícil de llevar a la práctica, pero posee la enorme ventaja de atravesar los ámbitos de la realidad empírica, social, el contexto cultural, y ayudarnos a comprender mejor el conjunto de la cultura.

Tal y como se ha dicho, para rastrear la parte material de las prácticas culturales desarrolladas en sociedad, debemos partir del hecho de que actualmente éstas no son más que registro arqueológico. Nuestra tarea es sacarlas a la luz partiendo de ese registro, y para ello creemos que la herramienta más adecuada es la descripción. En este sentido concreto, descripción no tiene nada que ver con la función clásica de la labor descriptiva tal y como se aplica en la Arqueología Tradicional; antes bien, por descripción se debe entender un relato auto-contenido que dé cuenta de las características básicas del registro arqueológico de una forma que sea lo más coherente posible con las propias características de ese registro y que no suponga manipular éste por introducir principios de descripción extraños u opuestos a su propia lógica original. Así pues, hablamos de descripción y no 
nos servimos de cualquier otro término que tal vez parecería más a la moda, para resaltar que uno de nuestros presupuestos básicos es intentar desprender al aparato analítico de matices interpretativos, dado que cualquier tipo de lectura interpretativa tiende a ser realizada siempre desde las bases de racionalidad actuales.

También hemos hecho uso de analogías 'débiles' (Vattimo, 1990) con las cuales se introduce un principio de racionalidad distinto del nuestro a través de la multiplicidad de significaciones, y que se han revelado como una potente herramienta de trabajo. En este caso se ha optado por observar la racionalidad implícita en el poblamiento tradicional y el poblamiento castreño para así obtener un contrapunto o marco de comparación con otras ajenas a la 'nuestra' y a la de la Edad del Bronce.

Hasta aquí los conceptos básicos que utilizaremos fundamentalmente en la primera parte del trabajo ya que, si bien se utilizarán de igual manera en la segunda, el grado de aproximación será menos intenso puesto que trataremos con una visión de tipo más general. Así pues, la primera parte constará en primer lugar de una descripción del conjunto de los yacimientos (descripción I) para, a continuación, realizar unas analogías con el poblamiento tradicional y el poblamiento castreño. Más tarde volveremos al ámbito de la descripción, pero esta vez ampliando la escala al interior de los yacimientos (descripción II), para acabar estableciendo un modelo coherente con las evidencias observadas en los anteriores apartados. En este sentido el establecimiento del modelo intenta traspasar el ámbito de la cultura material y el paisaje para adentrarse en el de las prácticas y, en última instancia, en el de la cultura.

La segunda parte del trabajo tratará más bien de indagar en el contexto socio-cultural de la realidad observada a lo largo de la primera parte. En este sentido revisaremos otras prácticas culturales de la Edad del Bronce gallega, fundamentalmente en lo que se refiere a la ocupación del espacio. Esta lectura nos permitirá no sólo completar nuestro modelo adecuadamente, sino también profundizar en el estudio de la forma cultural de apropiación del paisaje de la Edad del Bronce en el Noroeste y, en definitiva, aproximarnos al conocimiento de estas sociedades.

\section{AREAS DE ACUMULACIÓN: UN MODELO HABITACIONAL PARA LA EDAD DEL BRONCE EN EL NOROESTE}

\section{II.1. Los puntos documentados en la Sierra de O Bocelo (descripción I)}

Nuestro trabajo en la Sierra de O Bocelo, una vez realizada una prospección intensiva del conjunto de la zona de estudio (Criado Boado et alii, 1988 y 1991), que ha permitido reunir un conjunto relativamente amplio de yacimientos habitacionales de la Edad del Bronce (Méndez Fernández, 1991; Criado Boado et alii, 1991), consistirá en tratar de averiguar la conformación de esos yacimientos y sus inter-relaciones, intentando determinar la racionalidad que preside su emplazamiento (Méndez Fernández, 1989 y 1993a). No es nuestra misión en este momento fechar cada uno de los yacimientos. La cronología, en cambio, nos ayudará en su momento a aquilatar la definición espacial antes que limitarnos a dar una datación o a asignar cada yacimiento a un determinado periodo o fase (4).

Si observamos un mapa de distribución de los Puntos Arqueológicos (PAs) (Figs. 3, 4, y 5) de la época considerada, veremos que éstos pueden oscilar, si atendemos a los testimonios recuperados en cada uno de ellos, desde un único fragmento cerámico, hasta varios miles de fragmentos, además de líticos, estructuras, etc. Las actuaciones realizadas en ellos también son de distinto signo ya que varían, desde la simple prospección superficial, hasta las varias campañas de excavación, pasando por la prospección físico-química.

(4) La adscripción de los yacimientos considerados al II milenio a.C. en nuestro caso no ha resultado especialmente conflictiva puesto que, en el umbral superior, la cultura material se diferenciaba claramente de la del primer milenio (representada por los yacimientos fortificados de la Edad del Hierro, que presentan su primera datación en la zona en 2650 \pm 100 Bp y $2610 \pm 70$ Bp (Acuña Castroviejo y Meijide Cameselle, 1991: 52); mientras que el umbral inferior venía representado por las cerámicas inciso-metopadas también claramente diferenciables en el aspecto formal y con un encuadre cronológico comúnmente aceptado de finales del III milenio a.C. (González Méndez, 1991). Todo lo recuperado en prospección enmarcable entre estos dos horizontes se sitúa de una forma u otra (en lo que a cerámicas decoradas se refiere) en lo que podemos llamar tradición campaniforme o, en cualquier caso, estilísticamente dentro de la 'campaniformidad' (Prieto Martínez, 1993 y Boast, 1994). 
Lo primero que llama la atención en la distribución de estos PAs es su agrupamiento en lo que podemos denominar "Áreas de Acumulación" (AAs), dado que efectivamente los PAs se concentran de manera significativa en unas áreas y no en otras (Fig. 3). Estos agrupamientos ocupan una unidad topográfica singular, lo que contribuye al efecto de acumulación. Esta concurrencia de PAs en zonas concretas nos ofrece una primera definición de las áreas de acumulación, término que creemos se ajusta más a la realidad observada que el de yacimiento.

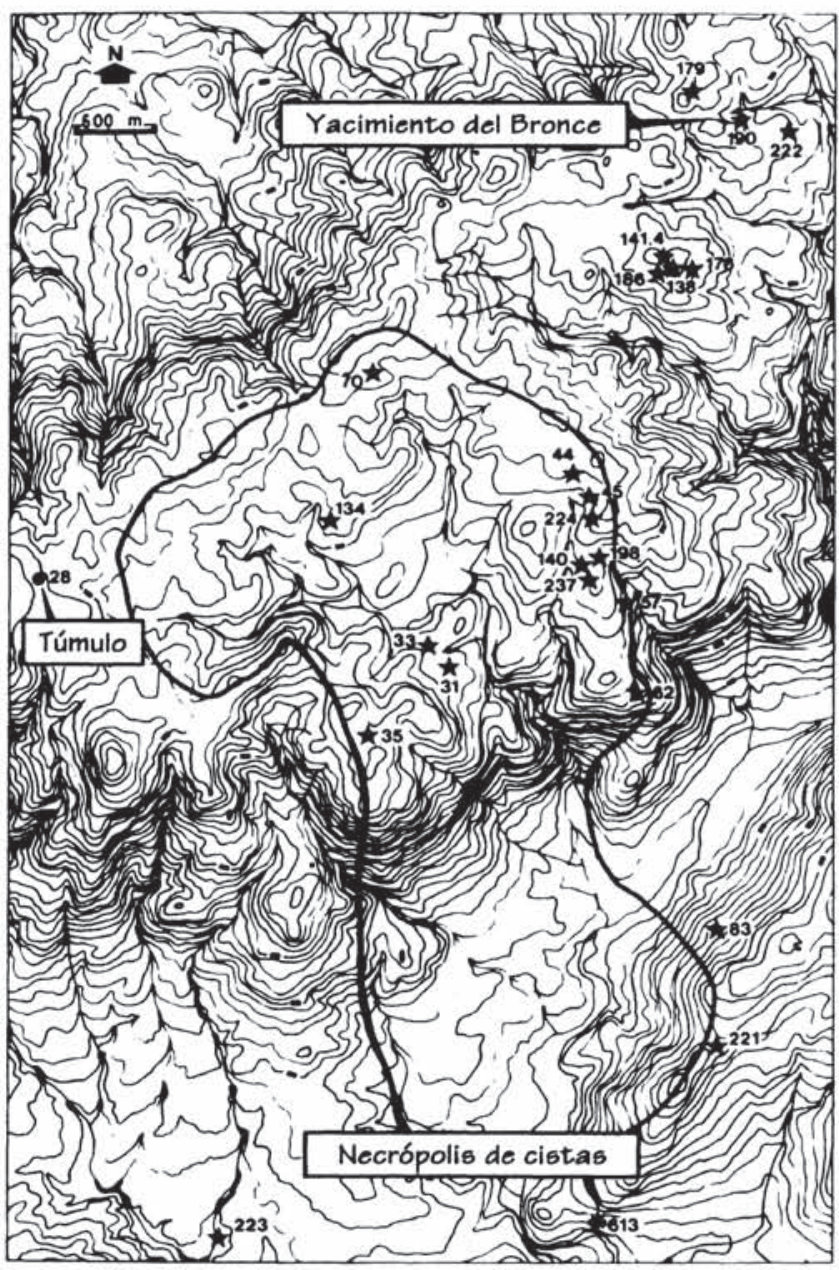

Fig. 3. Mapa de distribución de Puntos Arqueológicos del II milenio a.C. y situación del valle del Pedriña en el conjunto de la Sierra.

Para mayor comodidad y concreción trataremos a partir de este momento, únicamente con los yacimientos situados en un valle interior de la Sierra de O Bocelo. El Valle del Pedriña es el valle interior más amplio dentro de la Sierra y el que aglutina una mayor cantidad de núcleos de población actuales; asimismo este valle es el que ha ofrecido un mayor número de yacimientos de la época que nos ocupa.

Si tratamos de definir las unidades topográficas en las que se inscriben las áreas de acumulación, no sólo de forma cartográfica sino también visual, obtendremos como resultado que aquellas se instalan en pequeñas cuencas de recepción en cuyo fondo, generalmente, se sitúa una braña o pequeña turbera. Así, encontramos ahora que nuestro término área de acumulación adquiere un nuevo significado, dado que además se refiere al efecto aglutinador de las cuencas en donde se agrupan los PAs.

Aplicando una serie de sencillas técnicas espaciales, que en modo alguno tratan de definir un territorio sino de describir el entorno en el que se sitúan los yacimientos, observamos una serie de hechos sintomáticos (Méndez Fernández, 1989). En primer lugar, que la cuenca asociada se encuentra dentro de la línea isocrona de cinco minutos (Fig. 4). Asimismo el área de visibilidad directa desde un punto intermedio a todos los PAs que conforma cada área de acumulación, coincide con los límites de la cuenca y con la isocrona de cinco minutos (Fig. 5). Estos dos aspectos describen el entorno inmediato del yacimiento y nos confirman la estrecha relación existente entre los puntos correspondientes al área de acumulación y la cuenca.

En segundo lugar, dentro de la línea isocrona de diez minutos se encuentra un terreno de monte bajo bastante llano. De hecho las zonas de aparición de material se sitúan en una zona próxima a la ruptura de pendiente entre la cuenca y la zona llana. Las isocronas de diez minutos nos informan, además, sobre la relación de las AAs con las vías de tránsito secundarias (5), dado que aquellas se alargan en el sentido de la divisoria conectando todos los puntos considerados dentro del valle. La visibilidad indirecta (6), por su parte, nos permite la intervisibilización de las AAs del valle interior así como el perímetro del mismo.

(5) Es decir, aquellas que nos permiten circular por el interior de una unidad topográfica de primer orden, en contraposición a las primarias que nos permitirían cruzar o salvar esas unidades topográficas principales.

(6) Entendida como la visibilidad obtenida desde un punto próximo al yacimiento en el que nos situaríamos si pretendiésemos tener una visión amplia (este punto en ningún caso se aleja más de cincuenta metros del yacimiento) 


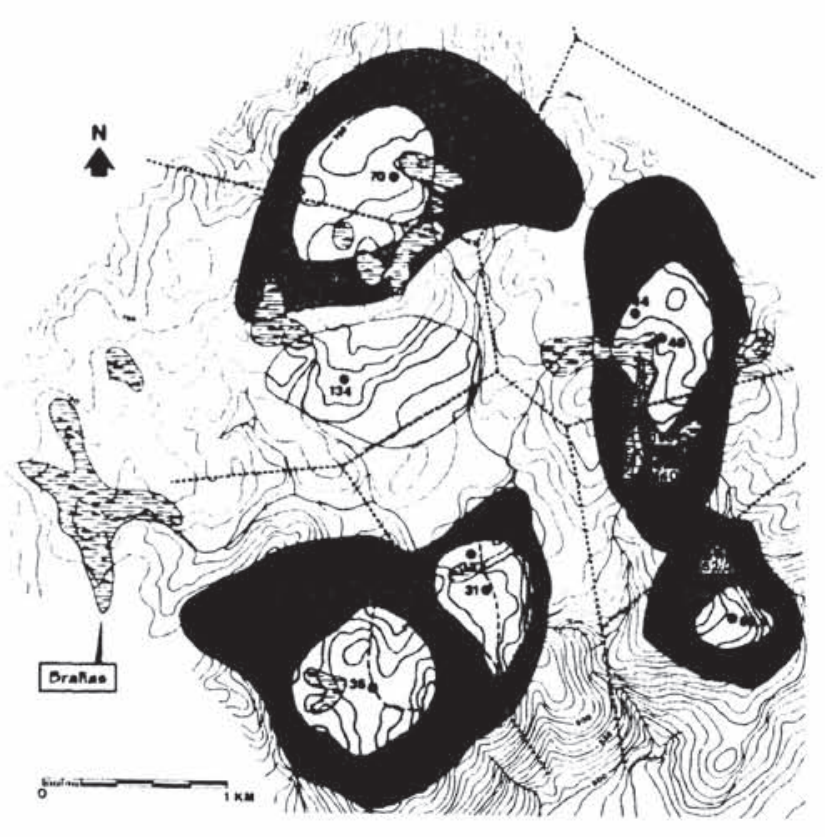

Fig. 4. Áreas isocrónicas de cinco y diez minutos de los yacimientos del valle del Pedriña. Se sitúan las brañas y se representan asimismo los polígonos de Thyessen de los yacimientos considerados.

El mapa de polígonos nos permite reforzar la concepción de AAs como suma de dos tipos de terreno: la cuenca húmeda y la zona llana aneja, coincidiendo con la isocrona de diez minutos.

\section{II.2. Analogías}

Aplicando al poblamiento tradicional un tratamiento similar al realizado para la Edad del Bronce, y cotejándolo con el de las AAs, nos encontramos con varios hechos significativos.

En primer lugar, las AAs y las aldeas actuales tienen una disposición parecida respecto al eje del valle pero no coincidente, es decir, nos encontramos con dos anillos concéntricos situados de forma periférica en relación al eje del río. Por otro lado, las AAs aparecen en el límite de la isocrona de diez minutos de las aldeas actuales, o bien en su inmediata periferia (Fig. 6). Todo el terreno incluido en este área isocrona está considerado etnográficamente como de monte (7) y constituye un campo excelente para

(7) El término monte no va unido en Galicia a terreno inculto, sino que más bien se refiere a un área de aprovechamiento extensivo agrícola y ganadero. En estas zonas se llevan a cabo cultivos de rozas, además de constituir zonas de re-

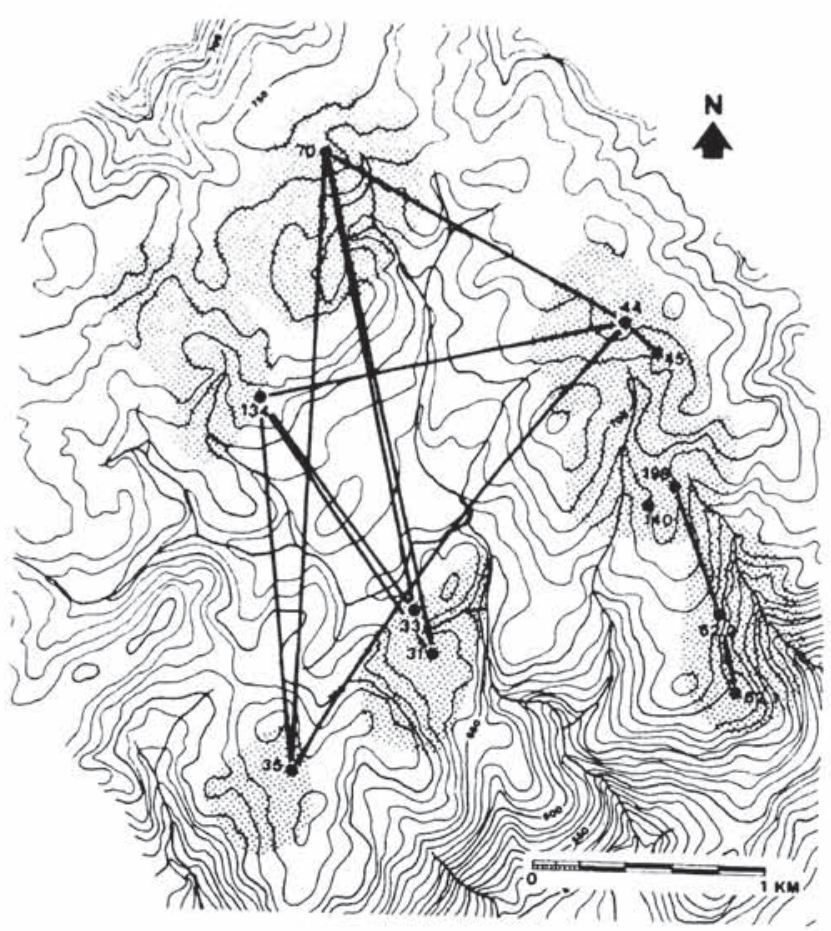

Fig. 5. Visibilidad directa e indirecta de los yacimientos considerados.

el cultivo de rozas. En cuanto los terrenos de labradío (8) actuales se encuentran mayoritariamente dentro de la isocrona de los cinco minutos de las aldeas y en su ámbito de visibilidad directa (Fig. 7).

Por su parte, los castros se disponen de una forma distinta con respecto al valle, ya que los dos únicos existentes se sitúan sobre el eje mismo, muy próximos al río. Por otro lado, estos yacimientos de la Edad del Hierro se encuentran en el ámbito de visibilidad de las aldeas e inmersos en las tierras de labradío.

De las consideraciones que se acaban de realizar sobre el poblamiento tradicional/castreño se pueden extraer una serie de consecuencias útiles para nuestro trabajo. De modo sumario se puede señalar que tanto las aldeas actuales como los castros pertenecen al dominio del labradío, dada su estrecha relación con las tierras

serva de toxo, fundamental para la elaboración de abono, y suponer un complemento importante para el mantenimiento de la cabaña ganadera.

(8) Con las tierras de labradío incluimos los prados tradicionales, ya que éstos se inscriben en el sistema de rotación de cultivos. Por otro lado, en los últimos años se viene dando un proceso en el que los labradíos van siendo sustituidos por prados que se orientan hacia la producción lechera. 


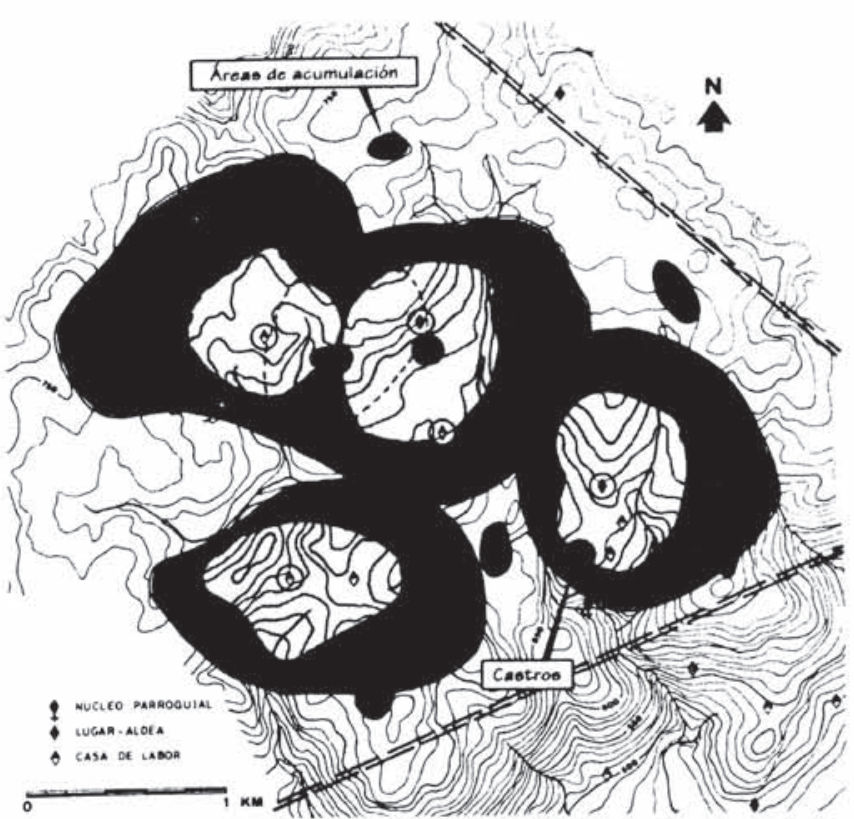

Fig. 6. Áreas isocrónicas de las aldeas actuales. Se representan también las áreas de acumulación y los castros. Las líneas rectas representan el límite del análisis en lo que se refiere a las aldeas actuales.

dedicadas a esta actividad. Sin embargo es necesario destacar que las AAs de la Edad del Bronce se emplazan en la periferia de esas zonas de labradío, y por tanto en el dominio del monte. Por otro lado, tanto las aldeas actuales como las AAs tienen una relación similar respecto al valle, en lo que se refiere a su posición periférica. La similitud entre ambas situaciones podría venir dada por el hecho de que en ambos momentos el valle fuese considerado como una unidad significativa (9).

\section{II.3. Descripción interna de las Áreas de Acumulación (descripción II)}

Los datos que se tratarán en este apartado corresponden al yacimiento de A Lagoa, una de las AAs del Valle del Pedriña a las que hemos aludido. Se trata del único yacimiento de sus características excavado con cierta extensión en el

(9) Esta afirmación es válida y comprobable para el poblamiento actual, ya que el valle constituye una parroquia, sin embargo este tipo de concepción no es, lógicamente, extrapolable para el caso prehistórico.

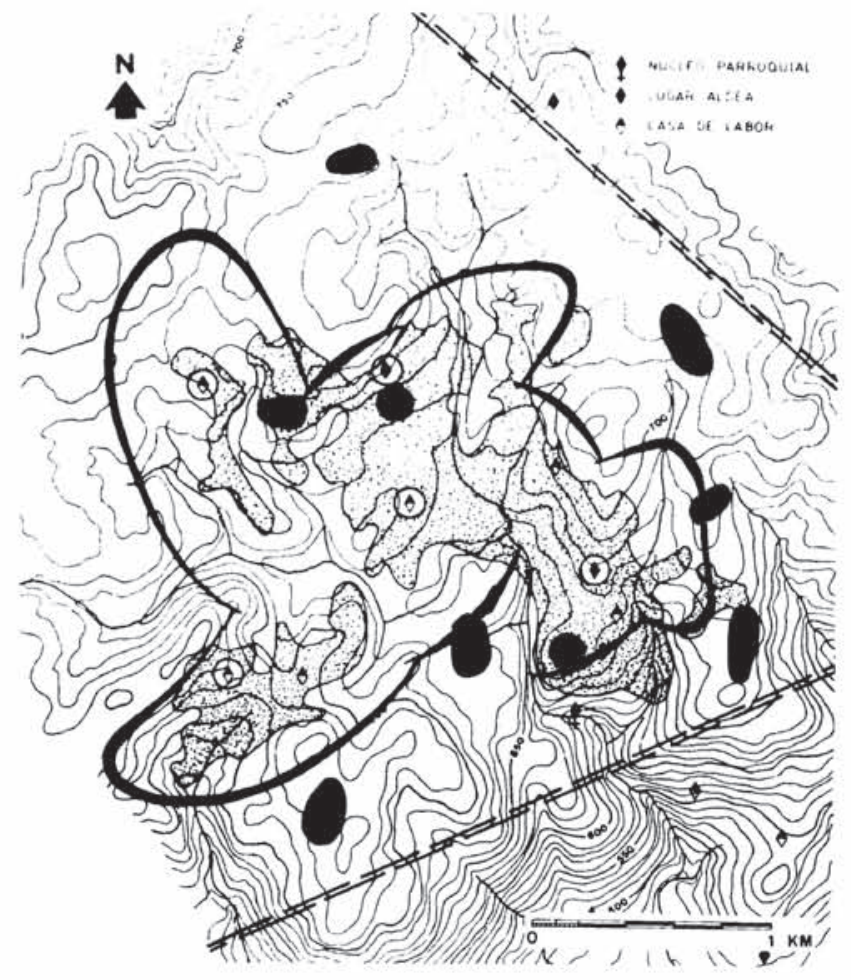

Fig. 7. Visibilidad de las aldeas actuales. Se representan las áreas de labradío y prados tradicionales, quedando en blanco las áreas de monte.

ámbito gallego (10). Los datos aportados por $\mathrm{A}$ Lagoa son suficientes para establecer unos rasgos definitorios que se pueden extrapolar al resto de las áreas de acumulación de la Sierra puesto que, como se ha dicho, el patrón que éstas presentan, así como sus rasgos externos son absolutamente equiparables.

El área ocupada por el yacimiento se extiende por lo menos en 8 hectáreas. Sin embargo, esta ocupación no es homogénea en toda la zona, sino que existen grandes y significativos vacíos, que hacen que no podamos hablar de una ocupación extensa y simultánea. Las estructuras de habitación localizadas (Fig. 8), reflejan un tipo de asentamiento no permanente, con cabañas de materiales perecederos, y probables estructuras de cierre de ganado también realizadas a base de postes. La impresión de no permanencia del poblamiento está reforzada por la

(10) Los trabajos en A Lagoa se han realizado entre los años 1987 y 1992, e incluyeron una campaña de prospección, dos de sondeo y tres de excavación. En total se han excavado más de $200 \mathrm{~m}^{2}$ en dos PAs diferentes. 

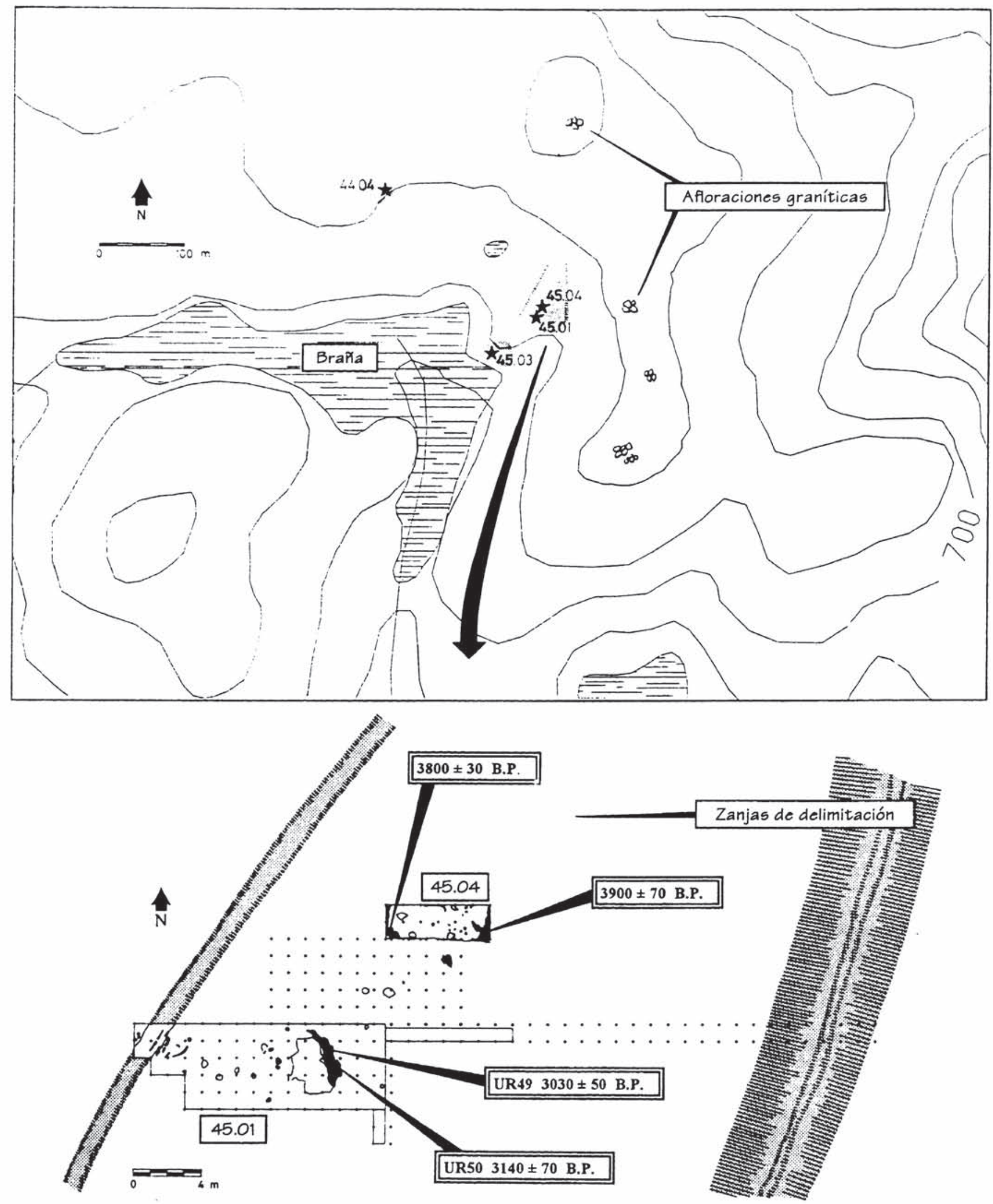

Fig. 8. (Arriba) Croquis de los principales Puntos Arqueológicos y Dispersiones del Área de acumulación de A Lagoa. (Abajo) Principales estructuras localizadas en los PAs 45.01 y 45.04, indicando las estructuras datadas.

\section{T.P., $51, \mathrm{n}^{\circ} 1,1994$}

(c) Consejo Superior de Investigaciones Científicas 
ausencia de estratificación entre las distintas estructuras (11).

Las dataciones radiocarbónicas efectuadas hasta el momento dejan clara la amplia perduración cronológica de la ocupación, si bien esto no significa, ni mucho menos que ésta sea continua. En la estructura contenida en el sector denominado 45.01 se han obtenido dos dataciones bastante coincidentes: $1080 \pm 50$ a.C. (CSIC900) y $1190 \pm 70$ a.C. (CSIC-901). En otra estructura, situada en el sector 45.04 , se obtuvieron dos fechas muy coherentes: $1950 \pm 70$ a.C. (CSIC- 899) y $1850 \pm 30$ a.C. (CSIC-1000) (12).

En cuanto a la cultura material, si bien las cerámicas decoradas aparecidas se encuentran dentro de la tradición campaniforme o estilísticamente inscritas en la campaniformidad, presentan una variabilidad de tipos bastante amplia, si se estudia en conjunto la cerámica de todo el yacimiento. Sin embargo no parece haber gran distancia estilística entre unos PAs y otros. Por tanto no es posible aquí realizar una aproximación cronológica a cada uno de los estilos representados (13). La datación tardía de la estructura del 45.01 puede resultar chocante en relación con las cerámicas campaniformes, sin embargo hemos de tener en cuenta que cada vez son más amplios los períodos atribuídos a este estilo cerámico (Boast, 1994 y Lull et alii, 1992: 92) (14).

Por último quisiéramos resaltar dos datos que presentan una gran relevancia, si bien necesitan algunas comprobaciones. Se han localizado estructuras tipo pequeño foso que delimitarían ciertas áreas del yacimiento. Por otro

(11) Con lo cual hoy en día se puede observar un palimpsesto que carece de desarrollo vertical.

(12) Todas las dataciones se realizaron sobre muestras de carbón vegetal.

(13) Este tipo de aproximación se puede observar en múltiples trabajos (Harrison, 1977 y 1988; Delibes de Castro, 1989 y Martín Valls y Delibes de Castro, 1989. Para el caso gallego puede verse Criado Boado y Vázquez Varela, 1982 y Fábregas Valcarce y Fuente Andrés, 1988). La línea evolutiva de los diferentes estilos campaniformes está en revisión en las Islas Británicas (lugar en el que se encontraban sólidamente establecidas desde los trabajos de Clarke en 1970) ya que no parece que sea sostenible a la luz de los últimos trabajos (Boast, 1993). La cerámica de A Lagoa ha sido estudiada sistemáticamente por Prieto Martínez (1993a y b).

(14) En el último caso se atribuye un umbral inferior para el campaniforme peninsular de 1650-1450 A.C. fecha en la que nos moveríamos si calibrásemos las dataciones recientes de A Lagoa. lado en un sector de excavación situado en las proximidades de uno de esos fosos, aparecen huellas de arado de tipo primitivo en el sustrato, que no se superponen con la ocupación principal del sector. Ambos testimonios se hallan en desconexión estratigráfica con las estructuras datadas. Esta desconexión estratigráfica no es un caso especial en estas estructuras, sino que todas las estructuras halladas se encuentran en estas mismas condiciones. Sin embargo existen datos que parecen apoyar la adscripción del foso y las huellas de arado a la Prehistoria (Méndez Fernández, 1991: 184).

De todo lo expuesto se deriva, en primer lugar, que la ocupación periódica se ha reiterado a lo largo del tiempo en la misma cuenca, esto explicaría la naturaleza de las estructuras y la amplitud del período cronológico abarcado. Nuestra denominación inicial de área de acumulación cobra una nueva dimensión, esta vez temporal.

Si se confirma la relación de los fosos con el yacimiento, nos encontramos ante un hecho de importancia capital, puesto que a pesar de lo episódico de la ocupación, se marca claramente el inicio de una parcelación del suelo que, en definitiva, supondría el inicio de algún tipo de propiedad de la tierra, de la cual no podemos precisar su alcance. Esta indeterminación no resta importancia al hecho en sí de la parcelación, puesto que aunque sólo supusiese la separación del espacio de la vivienda del espacio del cultivo y de los animales, significaría ya una cesura fundamental con las sociedades anteriores.

\section{II.4. Consecuencias socioeconómicas}

Todo lo que llevamos dicho no nos aclara por qué las áreas de acumulación se instalan en esos lugares que hemos descrito y no en otros. Este tipo de zonas son bastante abundantes en la parte media de la Sierra de O Bocelo, pero existen otras muchas posibilidades de emplazamiento, por lo que el patrón es suficientemente claro en lo que se refiere a este punto. El factor que unifica el patrón de emplazamiento es la existencia de cuencas húmedas, normalmente con brañas en su base.

Sin embargo, no todas las brañas existían en la época de ocupación del yacimiento, de hecho algunas de ellas comenzaron a formarse a raíz de tal ocupación, probablemente a causa de la deforestación asociada detectada en los análisis polínicos (Díaz Fierros et alii, 1991; Díaz Váz- 
quez et alii, 1992) Pero esta cuestión no invalida el razonamiento, ya que el clima durante el subboreal era más frío y seco que en la actualidad (Criado Boado. 1989). por lo que la sequía estival sería más aguda y el contraste entre la humedad de las cuencas de recepción (hoy brañas) y el resto del terreno más acusado.

Uno de los usos posibles de este tipo de cuencas sería el de la caza, dado que nos encontramos ante una zona atractiva para la práctica de la misma por sus buenas condiciones para encerrar y acosar el ganado. Tal disposición la encontramos en los yacimientos paleolíticos (Cerqueiro Landín, 1989: 117), que se sitúan en torno a las brañas más amplias de la Sierra, a pesar de que también son las menos resguardadas. Sin embargo, nuestras áreas de acumulación se localizan junto a brañas más resguardadas y con unas condiciones menos favorables para la caza.

En la actualidad (y más aún en el sistema tradicional) estas brañas tienen un uso específico, están destinadas a la reserva de pasto fresco de ganado vacuno ( $\mathrm{y}$ en menor medida equino) durante el verano. Esto viene motivado por la sequía estival que presenta el clima gallego. Por lo tanto, tenemos una utilidad evidente en este tipo de zonas, que sería tanto más provechosa cuanto que el contraste entre cuenca húmeda y terreno seco fuese más acusado.

Si tenemos en cuenta que, dados los testimonios que se recogen en el resto de Europa, la revolución de los productos secundarios resulta de una importancia capital en la época que nos ocupa (Sherrat, 1981 y 1987; Harrison y Moreno López, 1985), y que las áreas de acumulación no parecen ajenas a ella (recuérdense las huellas de arado en A Lagoa), podemos concluir que más que a la caza, la instalación en torno a cuencas húmedas está motivada por la necesidad de pasto fresco para el ganado. Más concretamente debemos referirnos al ganado vacuno, y no porque no existiese una explotación de ovicápridos o équidos (cuestión más que posible, aunque no dispongamos de indicios sobre ella), sino porque el grupo de los bóvidos es el que presenta unas mayores exigencias de alimentación. Por todo ello, consideramos que la ganadería de bóvidos resulta decisiva a la hora de la elección de un lugar de asentamiento en esta época. Lo que acabamos de decir no implica que ésta sea la única razón a tener en cuenta a la hora de la elección, ni que la ganadería vacuna sea un monocultivo en esta cultura.

Concedemos un valor adicional a la ganadería vacuna y es el de servir de mecanismo de aplazamiento del retorno y de acumulación de plustrabajo. Este mecanismo vendría dado, en uno de sus extremos, por la cantidad de trabajo necesaria para mantener una cabaña ganadera estable, en términos de labores estivales. Este trabajo estaría destinado a producir el alimento necesario para el ganado durante el invierno. En el otro polo, habría que incluir los rendimientos que se obtienen de ese trabajo (fuerza motriz para el tiro, leche, carne, piel, etc.), productos, todos ellos, que constituyen el retorno aplazado de la inversión realizada.

Hemos señalado anteriormente que la zona donde se encuentra el yacimiento se utiliza en la actualidad, y en el sistema agrario tradicional, para el cultivo de roza, que probablemente sería muy parecido a los prehistóricos (Criado Boado, 1989a), y aunque 'técnicamente' no resulta imposible el establecimiento de campos permanentes de labradío, esta zona no es la más apropiada para ello, y por tanto no se dan en la actualidad. Las huellas de arado mencionadas son perfectamente compatibles con una agricultura de este tipo, ya que, si bien las rozas pueden definirse como una 'agricultura de azada', la presencia de un arado ligero permitiría la ampliación de la superficie trabajada. Por otro lado, la agricultura de labradío propiamente dicha no se introduce en Galicia hasta la época castreña o, como mucho, en algunas zonas en la parte final de la Edad del Bronce. Esta última afirmación se deriva del hecho obvio de que una agricultura de campos permanentes debe ir indisolublemente aparejada a un tipo de hábitat permanente.

El interés por el mantenimiento de una cabaña ganadera estable ha de tener una motivación suplementaria a la meramente alimenticia, dado que la cantidad de alimento necesario para sostener una vaca es superior al producido por ésta. Las motivaciones suplementarias vendrían dadas, en nuestro caso, por la necesidad de una fuerza de tiro y probablemente por la existencia de algún tipo de abonado. Estas dos cuestiones constituyen innovaciones tecnológicas de primer orden. Ello no quiere decir que postulemos la existencia de una agricultura de labradío en estos momentos, al contra-

\section{T. P., $51, \mathrm{n}^{\circ} 1,1994$}


rio, proponemos el salto de la agricultura de roza primitiva a sus extremos más refinados $\mathrm{y}$, probablemente, a su límite tecnológico, que la hará desembocar al inicio de la Edad del Hierro en una agricultura de campos permanentes.

El tipo de agricultura que proponemos utiliza el mismo tipo de terreno que la realizada anteriormente, si bien puede abarcar, con la misma fuerza de trabajo, una extensión más amplia y obtener un mejor rendimiento durante más tiempo, gracias al abonado proporcionado por el ganado. Sin embargo, al cabo de, como mucho, tres o cuatro temporadas, se agotarían las tierras y habría que dejar paso a un ciclo regenerador. De ahí la no permanencia del hábitat y la imposibilidad del labradío.

\section{II.5. Concepto de Área de Acumulación}

Recapitulando todo lo expuesto sobre la áreas de acumulación, podemos definir éstas como zonas relacionadas con pequeñas cuencas húmedas, situadas en terrenos de monte, aptos para el cultivo de rozas. Estas zonas suelen ser periféricas respecto al valle principal y estar vinculadas a líneas de desplazamiento secundarias. La ocupación en estas áreas ha sido intermitente y recurrente a lo largo de todo el II milenio (15). La causa de su especial emplazamiento podría venir dada por la proximidad de zonas de reserva de pasto fresco durante el verano tanto como por la presencia en su entorno inmediato de tierras aptas para el cultivo de rozas, el cual podría ser realizado con arado ligero.

En su conjunto, el yacimiento se habría formado debido a la ocupación reiterada de pequeños grupos que basarían su subsistencia en una agricultura primitiva, aunque más 'refinada' técnicamente que la de las comunidades del Neolítico Final, en la que se incluiría una cabaña ganadera estable, fundamental para el desarrollo de algunos aspectos de este sistema agrícola. En este sentido se puede hablar de la progresiva constitución de la comunidad campesina que no se conformará plenamente hasta

(15) No creemos que este poblamiento pueda ser definido como estacional dado que, según el modelo propuesto, la habitación se mantendría a lo largo de varios años, mientras que un tipo de hábitat estacional se vincula a actividades que se realizan en una estación concreta. En este sentido urge una definición clara de tipos de poblamiento en el que se diferencien nítidamente términos como: nómada, itinerante, trashumante, estacional, etc que se habiten los primeros castros en la Edad del Hierro.

\section{EL CONTEXTO INMEDIATO DE LAS ÁREAS DE ACUMULACIÓN}

Las áreas de acumulación representan una forma de apropiación del espacio, pero en la misma sociedad en que se inscriben existen otras manifestaciones relacionadas con el espacio y el paisaje (v.g. enterramientos y grabados rupestres), que debemos tener en cuenta en nuestro modelo. Esto nos permitirá, de paso, observar el contexto inmediato de las áreas de acumulación. Con estos dos elementos estaremos en disposición de realizar una lectura más completa del contexto socio-cultural de las áreas de acumulación.

En O Bocelo disponemos de dos tipos de enterramientos distintos para esta época y dada la evidencia disponible para el resto de Galicia, incluiremos un tercero.

El primer tipo al que nos referiremos es el túmulo funerario de pequeño tamaño, no preeminente en el paisaje, probablemente de enterramiento individual. Se considera de cronología tardía en el conjunto de Galicia y el Norte de Portugal (Criado Boado y Vázquez Varela, 1982: 58-9 y 60-2; Criado Boado y Fábregas Valcarce, 1989a: 694; 1989b: 60; Jorge, V. O., 1988: 9-10). En O Bocelo este tipo se encuentra representado por el PA 28 (Criado Boado et alii, 1991), su posible adscripción a la Edad del Bronce nos ha sido facilitada por uno de sus excavadores (Criado Boado, com. per.) El segundo tipo es la cista funeraria sin túmulo formando 'necrópolis' con pequeñas fosas también sin túmulo (Meijide Cameselle, 1992) (16). Por último, cabe la posibilidad de que existan enterramientos secundarios en túmulos construidos en épocas anteriores (Calo Lourido y Sierra Rodríguez, 1983: 67; Rodríguez Casal, 1988: 72 y 1983), como ocurre en otras zonas de Galicia.

(16) La necrópolis está situada en la parte más baja del valle del Furelos, en contraposición a los hábitats que se encuentran en lo alto de la Sierra de O Bocelo. Las cistas y los materiales en ellas aparecidos (metalurgia, orfebrería y cerámicas) son uno de los objetos de estudio tradicionales en el Edad del Bronce gallega y han suscitado multitud de publicaciones (Harrison, 1974; Ruiz-Galvez Priego, 1984: 222-3, 414 y 423-5 y 1979; Vázquez Varela, 1980a y b, 1985-86, Hernando Gonzalo, 1983; Comendador Rey, 1991-2; etc.). 
Aunque no tenemos constancia de su estricta contemporaneidad, no es ésta la cuestión que nos ocupa en este momento, sino el encontrar un hilo conductor que nos informe acerca de su tendencia general. Este hilo conductor es que precisamente no existe una tendencia general clara en lo que a un tipo de enterramiento concreto se refiere. Sin embargo, sí existen unas características comunes a los tres: la disminución ostensible de la monumentalidad de cualquier tipo de construcción con respecto a situaciones anteriores, pudiendo interpretarse algunos casos, casi como estrategia de ocultación (caso de las cistas); y la generalización del enterramiento individual.

Podemos suponer que ambas tendencias coinciden en la conversión de los muertos del grupo en antepasados, frente a la consideración de ancestros de que deberían ser objeto en época megalítica (Criado Boado, 1989b). Por otro lado, si tenemos en cuenta la proliferación de objetos 'de prestigio' durante esta época tales como joyas de oro (17) o armas (18), nos encontraremos con que los elementos designadores del individuo se multiplican, siendo la primera vez en la Prehistoria del Noroeste que aparece tal fenómeno. Esto podría interpretarse como el inicio de la división social según el eje del poder (Clastres, 1981) de un mecanismo rector de la sociedad distinto de ella misma, pero también como el último intento desesperado de que tal no ocurra, negando al que se designa como individuo diferenciado del grupo social, la posibilidad de extender 'su poder' más allá de la muerte, relativizándolo de este modo en vida. En este último sentido, no debemos olvidar la pérdida de monumentalidad y por tanto de la presencia constante del muerto entre los vivos, que se daba en las sociedades megalíticas. El proceso de constitución del individuo, no sólo es totalmente coherente con el de la división social, sino que ambos lo son con el de la constitu-

(17) Éstas aparecen representadas en nuestra zona de estudio por el tesoro de Monte dos Mouros y un brazalete gallonado de oro (Melide, A Coruña) (López Cuevillas, 1933: 48-63; López Cuevillas y Bouza Brey, 1929: 30; Pérez Outeiriño, en prensa y Balseiro García, 1992) con paralelos y relaciones en el resto de Galicia y en toda el área atlántica (Monteagudo, 1953; Hernando Gonzalo, 1983; Ruiz-Gálvez Priego, 1979 y 1984)

(18) Se ha encontrado un puñal de espigo en un abrigo dentro de una de las áreas de acumulación de la sierra de $\mathrm{O}$ Bocelo. ción de la sociedad campesina que observabamos en las Áreas de Acumulación.

El comentario sobre los enterramientos nos ha permitido hacer un puente entre $\mathrm{O}$ Bocelo $\mathrm{y}$ el resto del Noroeste. De esta forma podremos adentrarnos en el ámbito habitacional de la Edad del Bronce Gallega. A este respecto los datos utilizables son parcos y se concentran en tres zonas geográficas fundamentales: la península del Morrazo y aledaños, el Norte de Portugal y la Sierra de O Bocelo. Los datos provenientes de los recientes trabajos arqueológicos, realizados con motivo de la construcción de la red de gasificación de Galicia y del Oleoducto Coruña-Vigo, han permitido descubrir un número elevado de yacimientos de este momento, sin embargo, estos datos son hasta ahora fragmentarios y por lo tanto no los utilizaremos in extenso (19). Podemos realizar una primera relectura de algunos aspectos a partir de las claves que nos aporta el concepto de las Áreas de Acumulación.

La pregunta inmediata es la de si los yacimientos en estas zonas son del mismo estilo que los de las Áreas de Acumulación o no. El yacimiento del que existe mayor información es el de O Fixón en la Península de O Morrazo, el cual ha sido objeto de diversas actuaciones arqueológicas y publicaciones parciales (GarcíaLastra, 1984; Suárez Otero, 1986 y 1993 y López García, 1984). Aparentemente, posee un nivel campaniforme y otro inferior con cerámicas lisas y elementos líticos (Suárez Otero, 1986: 26), con dataciones radiocarbónicas respectivas de $3830 \pm 130$ BP y $4820 \pm 120$ BP (García-Lastra, 1988: 176). También se ha localizado una aguja de cabeza enrollada perteneciente a la Edad del Bronce Final (Suárez Otero, 1986: 34). El yacimiento está situado a escasa distancia del mar en el interior de una cuenca bastante amplia, en la base de la cual se encuentra una zona húmeda. En la actualidad el relieve original está enmascarado por la presencia masiva de dunas. Evidentemente esta zona costera en la que muchos aspectos del poblamiento pueden estar condicionados por la presencia del mar no es comparable a la que hemos estudiado anteriormente. Sin embargo, nos interesa destacar tres

(19) Esto trabajos fueron realizados en virtud de un acuerdo entre la Dirección Xeral do Patrimonio Histórico e documental de la Consellería de Cultura de la Xunta de Galicia y la Universidad de Santiago, y fueron financiados por la primera institución y la empresa CLH. 
puntos. Por un lado, la vinculación del yacimiento con una cuenca más húmeda que su entorno. Por otro lado, la recurrencia de la ocupación a lo largo del tiempo, ya que (dejando de lado la cuestión del nivel precampaniforme que no nos incumbe en estos momentos) parece que va desde la introducción del campaniforme hasta, por lo menos, la Edad del Bronce Medio (Suárez Otero, 1993), con indicios de que se mantenga hasta la Edad del Bronce Final (Suárez Otero, 1986: 34). El último punto reseñable es la gran extensión del yacimiento.

A pesar de la amplia cronología del yacimiento, el registro estratigráfico no indica una sucesión progresiva en la ocupación, ni las estructuras localizadas (agujeros de poste, hogares, alguna pequeña fosa, etc. (García-Lastra, 1984 y Suárez Otero, 1993)) parecen tener la entidad suficiente para que podamos hablar de un hábitat permanente.

La extensa documentación de Alto da Caldeira/Tapado da Caldeira/Bouça do Frade en Baiâo (Norte de Portugal) (Jorge, S., 1980a y b, 1981 y 1988), permite su utilización como ejemplo habitacional de otra región del Noroeste. En una zona cuyos extremos están separados por seiscientos metros lineales (Jorge, S., 1981: 69) están documentadas ocupaciones en las que se encuentran representados grupos cerámicos como el campaniforme, Cogotas I, Baiôes o los vasos de largo borde horizontal (Jorge, S., 1980: 35 y ss. y 1988: 90). Por otro lado, las dataciones realizadas en el conjunto de la zona abarcan desde el 1340 a.C. hasta el 760 a.C. (Jorge, S., 1991: 213 y 221) (20). Sin embargo, la ocupación podría extenderse más allá del arco cubierto por las dataciones disponibles hasta el momento (Jorge, S., 1980a: 46), puesto que parece que no se han detectado en excavación estructuras vinculadas con el material campaniforme, por lo que, al menos, esta ocupación no está dentro de las dataciones obtenidas.

Estos dos ejemplos permiten mostrar cómo la recurrencia, que no permanencia, de la habitación en una misma zona resulta común a todos los hábitats mencionados. En el caso de $\mathrm{O}$ Fixón creemos que el interés en volver reiteradamente al mismo lugar puede ser justificado

(20) Cierto que en este arco están representadas tanto estructuras de habitación como funerarias, pero en cualquier caso, la cronología de los enterramientos sería aplicable a zonas habitacionales. por la presencia de la zona húmeda aludida anteriormente que constituye una reserva evidente de pasto fresco durante el verano. La cuestión parece discurrir por los mismos derroteros en el caso portugués citado ya que el conjunto de la estación se sitúa en una zona flanqueada por cuencas de recepción de pequeños ríos (Jorge, S., 1980a: 29), que si no individualmente, sí en su conjunto pueden aportar una reserva de pasto más que suficiente para el mantenimiento de una cabaña ganadera estable.

Junto a estos ejemplos, tenemos otros en los que se documenta al menos una ocupación singular: O Casal (Moaña) (Peña Santos, 1993) o Portecelo (O Rosal), cuyos excavadores proponen que el hábitat "aunque no fuese permanente, tampoco sería ocasional o pasajero" (Cano Pan y Vázquez Varela, 1988: 186), rasgo con el que estamos plenamente de acuerdo para cada una de las ocupaciones singulares de las Áreas de Acumulación, pero que necesita ser modelizado.

Para completar la visión que acabamos de ofrecer sobre los hábitats de la Edad del Bronce debemos mencionar un tipo específico de yacimientos que se ha venido denominando como de "fosas abiertas en el xabre" (Jorge, S., 1988: 91). Bouça do Frade (una de las zonas de la estación portuguesa mencionada) es uno de los paradigmas de este tipo de estaciones, aunque presenta una peculiaridad: es el único que por el momento se relaciona claramente con otros momentos de la Edad del Bronce. Otros casos parecen, en principio, desvinculados de otras ocupaciones: O Casal (Moaña) (Peña Santos, 1993). Si nos atenemos a los datos proporcionados por Bouça do Frade, hemos de convenir que la inexistencia de una relación entre las otras estaciones y otro tipo de ocupaciones de la Edad del Bronce (ya estén éstas vinculadas a cerámicas de tipo campaniforme o a cualquier otro tipo de conjunto cerámico del segundo milenio) es meramente circunstancial, ya que el entorno de las estaciones mencionadas no ha sido prospectado intensivamente (21) ni estos casos estudiados exhaustivamente.

Otro de los puntos que nos gustaría comentar en términos generales es el fenómeno de los grabados rupestres o petroglifos con una dispersión fundamentalmente costera y meridional

(21) Término que no es equivalente a prospectar repetidas veces (Criado et alii, 1988, 1989 y 1991) 
(Peña Santos y Vázquez Varela, 1979: 10), aunque con algunas prolongaciones en el Norte y el interior del país, que coinciden con zonas bien comunicadas naturalmente con la anterior. O Bocelo queda en una situación marginal con respecto al área nuclear. El marco cronológico de estas manifestaciones cubre el de nuestras áreas de acumulación dado que aquellos se han datado entre el Eneolítico y la Edad del Bronce Final (Peña Santos y Vázquez Varela, 1979: 100-6).

Dos son las cuestiones principales que se nos plantean. En primer lugar, debemos definir cuál es el contexto arqueológico de los petroglifos y más concretamente su relación con hábitats y/o enterramientos. Por otro lado, es necesario calibrar si el hecho de que los grabados rupestres se concentren en una zona restringida de Galicia tiene una correlación en la variación de otros aspectos (tipo de hábitat, base subsistencial, etc.), pudiendo evidenciar unas tradiciones culturales distintas. Lo cierto es que las preguntas planteadas no tienen una respuesta unívoca, sino que el camino a seguir es en ambos casos multidireccional.

En relación con la primera cuestión, resulta un tópico implícito y no formulado en la bibliografía gallega sobre el tema, el que los petroglifos no presentan una correlación clara con ningún otro tipo de yacimientos, ya sean éstos hábitats, enterramientos, etc. Este hecho quizá esté motivado por la tradición investigadora de los grabados rupestres que se centra con casi total exclusividad en cuestiones estilísticas, relación de motivos, distribuciones de éstos y cronología. Sin embargo, cada vez se van encontrando más casos de relación entre los petroglifos prehistóricos y otro tipo de yacimientos, que rompen la imagen unidimensional que teníamos del arte rupestre (22). Sí existen los yacimientos habitacionales relacionados con los petroglifos, aunque sean por el momento pocos los yacimientos y parcos los datos. Algunas referencias vinculan de forma genérica algún yacimiento a una estación concreta de arte rupestre:

(22) En los últimos años comienzan a desarrollarse trabajos en los que se estudian los grabados rupestres desde la perspectiva de la arqueología del paisaje. Estos trabajos están comenzando a dar sus frutos; en este sentido baste señalar a modo de ejemplos el trabajo de Victoria Villoch (en prensa) en el que se establece una estrecha vinculación entre un tipo de petroglifos con representaciones de cazoletas y túmulos funerarios, o en este mismo volumen Bradley et alii.
Portecelo (Cano Pan y Vázquez Varela, 1988: 186) y O Fixón (Suárez Otero, 1993). A pesar de ello, y hablando en términos genéricos, es ésta una cuestión en la que la escasez (que no falta) de datos se combina con la ausencia de trabajos interpretativos al respecto para ofrecer como resultado el estancamiento en el conocimiento. En lo que se refiere a nuevos aportes de evidencia empírica, las labores de seguimiento y control arqueológico de la construcción del oleoducto Coruña-Vigo, nos han permitido documentar yacimientos habitacionales relacionados con grabados rupestres que resultan enormemente prometedores.

Sin embargo por mencionar casos de yacimientos conocidos, citaremos el de O Fixón, que constituye un caso claro de coincidencia espacial y cronológica entre yacimientos tipo A Lagoa y petroglifos. La relación entre los grabados rupestres y el hábitat no se reduce a la mera proximidad (Suárez Otero, 1993). Si ampliamos un tanto nuestra perspectiva respecto al yacimiento, veremos que existen grupos de grabados (Patiño Gómez y Nores Soliño, 1987: 24-6; Suárez Otero, 1979; García Alén y Peña Santos, 1981) que rodean la cuenca asociada, lo cual refuerza la impresión de que, al menos para sus autores, es una unidad significativa. Además de esto, las zonas sondeadas del yacimiento se sitúan muy próximas de los petroglifos de Mogüelos (Suárez Otero, 1993). En éstos se representan dos escutiformes y un puñal que ha sido datado en una etapa avanzada de la Edad del Bronce (Peña Santos y Vázquez Varela, 1979: 91). Resumiendo, nos encontramos ante un yacimiento del estilo de las Áreas de Acumulación, con la particularidad de que la cuenca asociada está 'delimitada' por petroglifos que cronológicamente muy bien pudieran coincidir con el hábitat.

Respecto a la segunda pregunta planteada anteriormente, es obvio que la presencia o ausencia de petroglifos representa un acceso distinto al espacio (Criado Boado, 1993a: 32-4), dada la característica eminentemente visual y espacial de estas manifestaciones; en este sentido se puede afirmar que nos encontramos ante dos tradiciones distintas. Sin embargo, los yacimientos tipo Área de Acumulación (AA) y las áreas con petroglifos no parecen responder a condicionantes absolutamente dispares, puesto que, como hemos visto, se dan casos de convivencia de unos y otros. No queremos decir con 
esto que así se agoten, ni mucho menos, las posibles interpretaciones del problema, sine más bien al contrario, pues junto a esta lectura parcial pueden surgir otras muchas que poco a poco vayan eliminando el problema.

Es cierto que el entorno de los yacimientos del tipo de $A$ Lagoa es muy apto para determinadas actividades relacionadas con el ganado, pero esta circunstancia no debe de hacernos olvidar el hecho de que también lo son para el desarrollo de una agricultura de azada o de arado ligero. También se debe valorar el hecho de que tanto en A Lagoa como en otros yacimientos de su entorno geográfico y cronológico es común la aparición de molinos (por ejemplo en Fixón y Portecelo -véase Suárez Otero, 1993; Cano Pan y Vázquez Varela, 1988: 184). Sacamos esto a colación dado que algunas interpretaciones del arte rupestre relacionan a éste con actividades venatorias, punto con el cual no estamos, en principio, en desacuerdo (23). Lo que resultaría verdaderamente inverosímil sería considerar los grabados como la manifestación de una cultura entregada por entero a la caza y el pastoreo dadas las evidencias de cultivos (huellas de arado, polen de cereal datado en épocas anteriores a estos yacimientos, presencia de molinos en los yacimientos de estos momentos, etc.), las condiciones del emplazamiento y los datos registrados para la época en yacimientos peninsulares y europeos contemporáneos. Creemos en cambio que, al menos una parte significativa de los petroglifos, se relacionan con yacimientos del tipo que hemos examinado en $\mathrm{O}$ Bocelo, y que por tanto su base subsistencial incluye, como componente fundamental, una agricultura de un tipo 'primitivo evolucionado' a la que se añadiría un componente ganadero que, en algunos aspectos, es fundamental aunque ello no implique un tamaño desmesurado de la cabaña, ni tan siquiera que el aprovechamiento directo (alimentario) del ganado suponga el primer orden dentro de la base subsistencial de la época. Este modelo no es incompatible con un aprovechamiento, incluso intenso, de los recursos venatorios, aunque sí con una consideración exclusiva de éstos en términos de base subsistencial.

(23) Esta cuestion ha sido planteada para otras regiones europeas (Bradley, 1991: 80-2), su relación con los petroglifos gallegos puede verse en Criado Boado, 1993a: 32-4.
Concluyendo esta revisión y respondiendo simultáneamente al segundo de los interrogantes que nos planteábamos más arriba, las evidencias no apuntan hacia dos grupos culturales de base absolutamente dispar ya que, en ambos casos, hemos visto que coinciden ciertos aspectos del poblamiento con implicaciones directas en la base subsistencial y en el modelo de ocupación del territorio. Sin embargo también hemos percibido algunas diferencias notables, en lo que se refiere a la presencia o no de grabados rupestres y a la cuestión de los poblados de fosas.

En lo tocante a la primera cuestión estamos plenamente de acuerdo con la interpretación que de ella ofrece F. Criado (1993a: 33). Según este autor, "deberíamos entender los paisajes con y sin petroglifos como dos formas distintas de articular y configurar el mismo tipo de paisaje social". Creemos que así queda suficientemente recogido el hecho diferencial que supone la presencia de petroglifos, a la vez que se asume el hecho innegable de las similitudes entre los hábitats de una y otra zona. Por otro lado, con este tipo de lectura es posible establecer como hipótesis la existencia de una sociedad de tipo heroico en ambas zonas (Criado Boado, 1993); esto sería perfectamente compatible con el tipo de cuestiones que hemos repasado a lo largo del trabajo (surgimiento del individuo, mecanismos de aplazamiento del retorno que suponen un cierto grado de complejidad productiva, proceso de constitución de una sociedad campesina, etc.). Esta perspectiva abre una vía de investigación que ofrece grandes posibilidades en el futuro.

Los yacimientos de fosas es posible que sean una variación formal específica que acaece en un momento final o avanzado de la Edad del Bronce en la zona Sur de Galicia y en el Norte de Portugal, pero que habría mantenido, en lo esencial, el modelo económico-social que aquí se ha planteado. En otras zonas de Galicia, por ejemplo en O Bocelo y, tal vez, particularmente en las tierras interiores gallegas, este desarrollo específico de finales de la Edad del Bronce habría sido sustituido por la larga perduración de la tradición campaniforme que, de aceptar y generalizar el valor de las dataciones recuperadas en el yacimiento de A Lagoa, podría llegar a tener un abanico cronológico que cubriría alrededor de ocho siglos, desde principios de la Edad del Bronce hasta su horizonte final. 
Pese a las correspondencias o paralelismos que se puedan establecer entre las diferentes situaciones que de forma fragmentaria se empiezan a documentar, los extremos estudiados para el conjunto de Galicia desembocan en una conclusión clara: no existe un paisaje de la Edad del Bronce en Galicia, sino diversos paisajes que, en algunos casos, vienen dados por distintas combinaciones de aspectos diferentes. Comienza a ser urgente analizar estas variaciones de cara a establecer una comarcalización (24). En el polo opuesto se ha podido ver que existen multitud de aspectos comunes a todos estos paisajes y que, en definitiva, en ocasiones resulta rentable remontarse sobre los aspectos parciales y diferenciadores para centrarse en aquellos otros que pueden informarnos acerca de las tendencias generales. En definitiva, al final de nuestros caminos descubrimos que éstos unicamente nos conducían, como casi siempre, al inicio de muchos otros.

\section{BIBLIOGRAFÍA}

Acuña Castroviejo, F. y Meijide Camesel.l.e, G. (1991): "Castro de A Graña (Toques, A Coruña)". Arqueoloxía/Informes 2. Campaña de 1988: 51-4. D.X.P.H.D. Consellería de Cultura e Xuventude. Xunta de Galicia.

Balseiro García, A. (1992): "Orfebrería antigua da Terra de Melide". Boletín do Centro de Estudios Melidenses, 7. Museo Terra de Melide: 15-26. Melide.

Barretr, J. C. (1994): "Fragments from Antiquity. An Archaelogy of Social Life in Britain, 2900-1200 BC". Blacwell. Oxford UK \& Cambridge USA.

BOAST, R. (1994): "Pattern by design: changing perspectives of beaker variation". En M. Edmonds y C. Richards (eds.): "Social Life and Social Change: The Neolithic of North Western Europe". Routledge. London (en prensa).

(24) Este tipo de trabajo ha sido realizado para el caso megalítico sobre una 'provincia' concreta (Criado et alii, 1990-91), y para el caso castreño (Carballo Arceo et alii, 1988). Evidentemente un trabajo de esta naturaleza sobre la Edad del Bronce debería conjugarse con otros del mismo estilo realizados en épocas anteriores y posteriores. Los primeros atisbos de esta comarcalización durante la Edad del Bronce pueden entreverse en algunos de los aspectos que hemos tocado en este trabajo, dado que, por ejemplo, se observa que la aparición de los yacimientos de fosas (al menos en los casos gallegos) en el tramo final del período coincide aproximadamente con el área nuclear de los petroglifos, mientras que las zonas en que se mantiene la tradición campaniforme hasta momentos más tardíos parece concentrarse más al interior.
Bol rdit:. P. (1991): "El sentido práctico". Taurus Ediciones $\left(1^{\star}\right.$ edición en francés 1980$)$. Madrid.

BRADI.Y.Y. R. (1991): "Rock art and the perception of landscape". Cambridge Archaeological Journal, I: 77. 107. Cambridge.

BRADI.FY, R.: (RIADO BOADO, F. y FABRE(iAS VAI.CARCE. R. (1994): "Los petroglifos como forma de apropiación del espacio: estudio basado en ejemplos gallegos“. Trabajos de Prehistoria, 51, 2.

Cal.u Lourido. F. y Silkra Rodriguez, X. C. (1983): "As oríxenes do castrexo no bronce final". En G. Pereira Menaut (ed.): "Estudios de cultura castrexa e de historia antigua de Galicia". Universidade de Santiago de Compostela: 19-85. Santiago de Compostela.

Cano Pan, J. A. y Vazouez Varei.a, J. M. (1988): "Portecelo un yacimiento de la Edad del Bronce". Trabalhos de Antropologia e Etnología. XXVIII (Fasc. 1-2). Actas do coloquio de Arqueología do Noroeste Peninsular (Porto-Baiâo, 1988): 181-7. Porto.

Carballo Archo, L. X.; Naveiro lópez, J. L. y Rey CASTINEeIRA, P. (1988): "Problemas de compartimentación espacial do castrexo Galaico". Trabalhos de Antropología e Etnología. XXVIII (Fasc. 3-4). Colóquio de Arqueologia do NW Peninsular (Porto-Baiâo, 1988): 168-83. Porto

Cerqueiro landin. D. (1991): "Industrias líticas: un pasado difuso". En F. Criado Boado et alii (1991): 97128.

Cl.ARKE, D. L. (1970): "Beaker pottery of Great Britain and Ireland". Gulbenkian archaeological series. Cambridge University Press. Cambridge.

Clastres, P. (1981): "Investigaciones en antropología política”. Gedisa. Barcelona.

COMENDAdOR REY, B. (1991-92): "Los inicios de la metalurgia: primeros testimonios de la provincia de Pontevedra". Brigantium, 7: 185-204. Museo Arqueolóxico e Histórico. A Coruña.

Criado Boado, F. (1989)a: "Contribución al estudio de las relaciones entre comunidades megalíticas del Noroeste Peninsular y su medio natural: implicaciones socio-económicas". Tesis Doctoral inédita. Facultade de Xeografía e Historia. Santiago de Compostela.

- (1989)b: "Megalitos, espacio, pensamiento". Trabajos de Prehistoria, 46: 75-98. Madrid.

- (1993)a: "Límites y posibilidades de la Arqueología del Paisaje". Spal (en prensa). Sevilla.

- (1993)b: "Visibilidad e interpretación del registro arqueológico". Trabajos de Prehistoria, 50: 39-56. Madrid.

Criado Boado, F.; Bonilla Rodríguez, A.; Cerqueiro Landin, D.; González Méndez, M.; Méndez Fernández, F. y Penedo Romero, R. (1988): "Proyecto Bocelo-Furelos: arqueología del paisaje y prospección intensiva en Galicia". Trabalhos de Antropología e Etnología. XXVIII (Fasc. 1-2). Actas do coloquio de Arqueología do Noroeste Peninsular (Porto-Baiâo, 1988): 241-50. Porto.

Criado Boado, F.; Bonilla Rodriguez, A.; Cerqueiro LANdín, D.; Díaz VÁzQuez, M.; GonzÁlez MÉndez, M.; Infante Roura, F.; MÉndez Fernández, F.; Penedo Romero, R.; Rodriguez Puentes, E. y VA- 
QHiro LASTRES, J. (1991): “Arqueología del Paisaje: el área Bocelo-Furelos entre los tiempos paleoliticos y los medievales (Campañas de 1987. 1988 y 1989)". Arqueoloxia-Investigación, 6. Consellería de Cultura. Santiago de Compostela.

Criado Boado, F. y Fabregas Valcarce, R. (1989)a: "The megalitic phenomenon of northwest Spain: main trends". Antiquity, 63: 682-96.

- (1989)b: "Aspectos generales del megalitismo galaico". Arqueologia, 19: 48-63. Porto.

Criado Boado, F. y Fábregas Valcarce, R. y VaQUERO LASTRES, J. (1990-91): “Concentraciones de túmulos y vías naturales de acceso al interior de Galicia”. Portugalia, Nóva Série. XI-XII: 27-38. Porto.

Criado Boado, F. y Vazouez Varei.A, J. M. (1982): "La cerámica campaniforme en Galicia”. Cuadernos do Se. minario de Sargadelos, 42. Edicións O Castro. A Coruña

Delibes de Castro, G. (1989): "Calcolítico y vaso campaniforme en el Noroeste Peninsular". Boletín del Seminario de Estudios de Arte y Arqueología, LV: 41-59. Valladolid.

Diaz Fierros, F., Aira Rodríguez, M. J., Criado BoADO, F., Y TABOADA, T. (1991): "Paleoecologia y prehistoria de un paisaje rural". Edicións O Castro. A Coruña (en prensa).

Diaz VÁzQUez, M.: Criado Boado. F. y Mendiz. FERNÁNDEZ, F. (1992): "Dinámica de pendientes y acción antrópica en Galicia durante el Holoceno Reciente: un caso de estudio derivado de la Sierra de O Bocelo (Coruña)". II Reunión de GeoArqueología (Madrid, diciembre de 1992), en prensa

FÁbregas VAlCARCE, R. y Fuente, F. de la (1988): “Aproximaciones a la cultura material del megalitismo gallego: la industria lítica pulimentada y el material cerámico". Arqueohistórica, 2. Tórculo Edicións. Santiago de Compostela.

García Alén, A. y Peña Santos, A. de la (1981): "Grabados rupestres de la Provincia de Pontevedra". Fundación Pedro Barrié de la Maza. A Coruña.

Garcia-Lastra Merino, M. (1984): "Primeros resultados de las campañas arqueológicas de excavaciones arqueológicas 1982, en el yacimiento de O Fixón (Hío, Cangas de Morrazo)". Pontevedra Arqueológica, I: 113-44. Pontevedra.

- (1988): "Aportación a la cronología campaniforme del Noroeste". Trabalhos de Antropología e Etnología, XXVIII (Fasc. 1-2). Actas do coloquio de Arqueología do Noroeste Peninsular (Porto-Baiâo, 1988): 175-9. Porto.

GonZÁlez MéndeZ, M. (1991): “Yacimientos del III milenio a.C.: entre la problemática del Calcolítico y un pasado huidizo". En F. Criado Boado et alii (1991): 14772.

Harrison, R. J. (1974): “A closed find from Cañada Rosal, prov. Sevilla and two bell beakers". Madrider Mitteilungen, 15: 77-94.

(1977): "The Bell Beaker Cultures of Spain and Portugal". Peabody Museum of Archaeology and Ethnology. Harvard University, Cambridge, Massachusets.
- (1988): "Bell Beakers in Spain and Portugal: working with radiocarbon dates in the 3 rd millennium $\mathrm{BC}^{\circ}$." Antiquity, 62. 236: $464-472$.

HARRISON, R. J. y MORI VO LOPI 7. (i. (1985): "El policultivo ganadero o la revolución de los productos secundarios". Trabajos de Prehistoria, 42: 51-82. Madrid.

Hernando Gonzal.o. A. (1983): "La orfebrería durante el Calcolítico y el Bronce Antiguo en la Península Ibérica". Trabajos de Prehistoria, 40: 85-138. Madrid.

Jorgt, S. O. (1980)a: “A estaçao arqueológica do Tapado da Caldeira (Baiâo)". Portugalia. Nóva Séric I: 29-50. Porto.

- (1980)b: "A necrópole do Tapado da Caldeira-Baiâo". Arqueologia, 2: 36-44. Porto.

- (1981): "Sondagens arqueológicas na estaçao do Alto da Caldeira". Arqueología, 3: 67-76. Porto.

- (1988): "O Povoado da Bouça do Frade (Baiâo) no quadro do Bronze Final do Norte de Portugal". Monografias Arqueológicas 2 do Grupo de Estudios Arqueológicos do Porto. Porto.

- (1991): "Datas de Carbono 14 para a Pré-Historia recente do Norte de Portugal: os dados e os problemas". En S. O. Jorge y V. O. Jorge (1991). "Incursoes na Pré-Historia". Fundação eng. Antonio de Almeida: 209-55. Porto.

JOR(iE, V. O. (1988): "Campo Arqueológico da Serra da Aboboreira, Arqueología do Concelho de Baiâo. Resultados de 10 anos de trabalho". Arqueologia, 17: 526. Porto.

LÉvi-Strauss, C. (1964): "El pensamiento salvaje". Fondo de Cultura Económica ( $1^{a}$ edición en francés 1962). México.

- (1992): “Tristes Trópicos”. Paidós Básica (1ª edición en francés 1955). Barcelona.

LÓPEZ CUEVILl.As, F. (1933): "Prehistoria de Melide". En VV.AA. "Terra de Melide": 31-184. Seminario de Estudios Galegos. Santiago de Compostela.

LÓPEZ CUeVIllas, F. y Bouza Brey. F. (1929): "Os Oestrimnios, os Saefes e a Ofiolatría en Galiza". Nos. A Coruña.

LÓPEZ García, P. (1984): “Análisis palinológico de los sedimentos arqueológicos del yacimientos de 'O Fixón'”. Pontevedra Arqueológica, I: 145-8. Pontevedra.

Lull, V., González Marcén, P. y Risch, R. (1992): “Arqueología de Europa, 2250-1200 A.C. Una introducción a la 'Edad del Bronce'”. Editorial Síntesis. Madrid.

Martín Valls, R. y Delibes de Castro, G. (1989): La cultura del vaso campaniforme en las campiñas meridionales del Duero. El enterramiento de Fuente-Olmedo (Valladolid). Monografía del Museo Arqueológico de Valladolid, 1 ( $2^{\text {a }}$ edición aumentada). Junta de Castilla y León. Valladolid.

Meijide Cameselle, G. (1992): “A necropole do Agro de Nogueira (Piñeiro, Toques): un paso fundamental para o coñecemento da Idade do Bronce en Galicia". Boletín do Centro de Estudios Melidenses, 7: 7-14. Museo da Terra de Melide. Melide.

MÉndez FERnÁnDEZ, F. (1989): Ocupación del Valle del Pedriña durante el campaniforme tardio. Trabajo de Investigación del Tercer Ciclo inédito. Facultade de Xeografía e Historia. Santiago de Compostela. 
- (1991): "El campaniforme tardio: entre un pasado monumental y una cerámica conspicua". En F. Criado Boado et alii (1991): 173-98.

- (1993)a: “Áreas de Acumulación: un modelo de yacimiento habitacional para la Edad del Bronce en Galicia". Actas del XXII Congreso Nacional de Arqueología, celebrado entre el 17 y el 20 de noviembre de 1993. Vigo (en prensa).

- (1993)b: "Relectura del registro arqueológico de la Edad del Bronce en Galicia". Actas del XXII Congreso Nacional de Arqueología, celebrado entre el 17 y el 20 de noviembre de 1993. Vigo (en prensa).

Monteagudo, L. (1953): "Orfebrería del NW hispánico en la Edad del Bronce". Archivo Español de Arqueologia, 26: 269-312. Madrid.

Patiño Gómez, R. y Nores Soliño, A. (1987): A Prehistoria de Cangas. Serie Traballos de Arqueología I. Publicación do Grupo de Arqueología "Alfredo García Alén" R.P. Edicións. A Garda.

Peña Santos, A. de la (1989): "El primer milenio a. C. en el área gallega: Génesis y desarrollo del mundo castreño a la luz de la arqueología”. En M. Almagro Gorbea y G. Ruiz Zapatero (eds.): "Paleoetnología de la Peninsula Ibérica". Actas de la reunión sobre etnogénesis de la Peninsula Ibérica. 1989. Complutum 2-3: 373 394 Madrid.

Peña Santos, A. de la, y Vazquez Varela, J. M. (1976): "Los petroglifos de Galicia. Grabados rupestres prehistóricos al aire libre en Galicia". Cuadernos do Seminario de Sargadelos, 30. Edicións do Castro. A Coruña.

Pérez OUteiriño, B. (1994): "Primeras manifestaciones da ourivesaria do NW Peninsular" (en prensa).

Prieto Martínez, P. (1993)a: Aproximación al análisis formal de la cerámica de la Edad del Bronce en Galicia. Trabajo de Investigación del Tercer Ciclo inédito. Facultade de Xeografía e Historia. Santiago de Compostela.

- (1993)b: "Definición de un sistema metodológico para el estudio de la cerámica de la Edad del Bronce en Galicia: La Tradición Campaniforme del yacimiento de A Lagoa (Toques, A Coruña)". Actas del XXII Congreso Nacional de Arqueología, celebrado entre el 17 y el 20 de noviembre de 1993 . Vigo (en prensa).

Rodriguez Casal, A. (1983): "A mámoa de Monte Campelos e o seu enterramento secundario. Novos datos encol do Megalítico Final Galego". Boletín do Museo Provincial de Lugo, 1: 7-17. Lugo.

- (1989): La necrópolis megalítica de Parxubeira. Monografías Urxentes do Museu, 4. Museo Arqueológico e Histórico. A Coruña.
Ruiz-Galvez Priego, M. L. (1979): "El Bronce Antiguo en la Fachada Atlántica peninsular: un ensayo de periodización". Trabajos de Prehistoria, 36: 151-72. Madrid

- (1984): "La Península Ibérica y sus relaciones con el circulo cultural atlántico". Universidad Complutense. Tesis Doctoral. Madrid.

Shanks. M. y Tilley, C. (1992): "Re-Constructing Archaeology. Theory and Practice". Routledge ( $1^{\text {a }}$ edición 1987). London \& New York.

SherRAT, A. (1981): "Plough and pastoralism: aspects of the secondary products revolution". In I. Hodder; G. Isaac, N. Hammond (comps.): "Pattern of past". Cambridge University Press: 261-305. Cambridge.

- (1987): "Cups that cheered". In W. H. Waldren \& R. Kennard (eds.): "Bell Beaker of the western mediterranean. Definition, interpretation, theory and new site data". The Oxford International Conference 1986. BAR International Series, 331: 81-114.

SuÁrez OTERo, J. (1979): “'Os Olleiros', nova estación do arte rupestre galego". El Museo de Pontevedra, XXXIII: 101-27.

- (1986): A Idade do Bronce en Galicia: aspectos ceramolóxicos. $O$ Bronce Inicial. Tesis de Licenciatura inédita. Facultade de Xeografía e Historia. Santiago de Compostela.

- (1993): "O Fixón: una nueva perspectiva del Bronce Inicial en Galicia". Comunicación presentada a las $A c$ tas del XXII Congreso Nacional de Arqueología, celebrado entre el 17 y el 20 de noviembre de 1993. Vigo (en prensa).

VÁzQUEZ VARELA, J. M. (1980)a: "Enterramientos en cista de la Edad del Bronce en Galicia”. Pontevedra, 0: 23-40. Pontevedra.

- (1980)b: "Cistas decoradas en Galicia: una nueva manifestación artística de la Edad del Bronce". Brigantium, 1: 41-8. A Coruña.

- (1985-86): "Nueva cista decorada del Bronce Inicial en Galicia”. Pontevedra Arqueológica, II: 91-5. Pontevedra.

VAтtiмO, G. (1991): "El fin de la modernidad. Nihilismo y hermenéutica en la cultura postmoderna". Gedisa. Barcelona.

Veyne, P. (1984): "Cómo se escribe la Historia. Foucault revoluciona la Historia”. Alianza Universidad. Madrid.

Villoch VÁzquez, V. (1993): "Análisis del emplazamiento tumular en Galicia: el caso de la necrópolis de Saídos das Rozas (Campolameiro, Pontevedra)". Actas del XXII Congreso Nacional de Arqueología, celebrado entre el 17 y el 20 de noviembre de 1993 . Vigo (en prensa). 